\title{
Treatment of aortic dissection involving the right coronary
}

Ermanno Bellanti, MD, Lorenzo Bagozzi, MD, Gino Gerosa, MD, and Tomaso Bottio, MD, PhD, Padua, Italy

From the Division of Cardiac Surgery, Department of Cardiac, Thoracic and Vascular Sciences, University of Padua, Padua, Italy.

Drs Bellanti and Bagozzi contributed equally.

Disclosures: Authors have nothing to disclose with regard to commercial support.

Received for publication March 28, 2018; revisions received May 20, 2018; accepted for publication May 28, 2018; available ahead of print July 13, 2018.

Address for reprints: Tomaso Bottio, MD, PhD, Cardiac Surgery Unit, Via Giustiniani, 2, 35128, Padua, Italy (E-mail: tomaso.bottio@unipd.it or tbottio@gmail.com).

J Thorac Cardiovasc Surg 2018;156:2084-6

$0022-5223 / \$ 36.00$

Copyright $(c) 2018$ by The American Association for Thoracic Surgery

https://doi.org/10.1016/j.jtcvs.2018.05.103

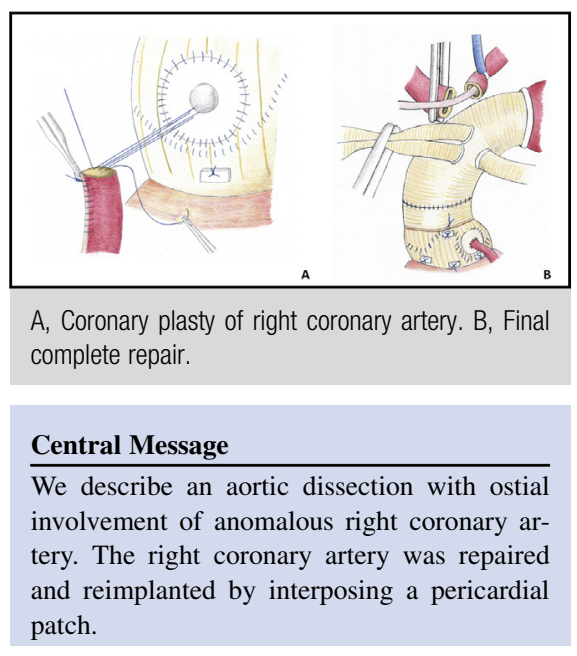

See Editorial Commentary page 2087
Aortic dissection with flap extension into coronary arteries still represents a surgical challenge. In this report, we report a case of type A aortic dissection with ostial involvement of an anomalous right coronary artery (RCA) origin and intramural path. After Tirone David valve-sparing aortic root and arch replacement, the RCA was repaired and reimplanted onto the Dacron polyester fabric prosthesis by interposing a pericardial patch. We suggest a new approach to coronary artery reimplantation, providing a more physiologic anastomosis with respect to the anatomic pattern. The institutional review board has approved this article.

\section{TECHNIQUE}

A 60-year-old woman was referred to the emergency department because of chest and left leg pain. Computed tomographic angiographic scans revealed a type A aortic dissection that extended form the aortic root to the iliac vessels (Figure 1, $A-C$ ).

Cardiopulmonary bypass was established through the right axillary artery and the right femoral vein. An additional venous drain was placed into the superior vena cava. One-shot cold crystalloid HKT Custodiol cardioplegia (Essential Pharmaceuticals LLC, Durham, NC) was administered into the coronary ostia, and $22^{\circ} \mathrm{C}$ of hypothermia was achieved. At the surgical inspection, we found that the dissection flap involved the RCA. Moreover, the right coronary ostium was above the sinotubular junction, and the course was intramural in its proximal tract (Figure 2, A). Because the aortic valve was preserved but the aortic root was involved, we opted for a valve-sparing aortic root replacement, which was performed according to the Tirone David type I technique. The RCA was reconstructed in 3 subsequent steps: (1) by shortening the proximal intramural portion with elimination of the dissected tract (Figure 2, B); (2) by reinforcing the distal intramural tract, once isolated from the sinus aorta, suturing together the RCA's layers with aortic wall remnants (Figure 2, C); and (3) by interposing a bovine pericardial patch to anastomose the reconstructed RCA (Figure 3, $A$ and $B$ ). This alternative surgical technique was intended to create new, pliable coronary ostium, to avoid vessel distortion, and to facilitate the execution of anastomosis. With the patient receiving selective anterograde cerebral perfusion, the aortic arch was examined. The flap dissection involved the first 2 supra-aortic vessels. The aortic arch was replaced with a Dacron polyester fabric prosthesis with 2-plus-1 side branches. The left subclavian artery was not involved by the dissection and originated from the true lumen; for these reasons, it was not reimplanted. Cerebral monitoring was performed by continuous measurement of cerebral oxygen saturation (INVOSTM; Medtronic Inc, Minneapolis, Minn). Surgical times were as follows: ischemic time of 220 minutes, cardiopulmonary bypass time of 350 minutes, and selective cerebral perfusion time of 60 minutes. Transesophageal echocardiography revealed a normal biventricular function without hypokinesia areas and the perfect competence of the aortic valve.

The patient's extubation was possible within a few hours after surgery, and the zenith troponin level was $30.526 \mathrm{ng} / \mathrm{L}$. No surgery-related or neurologic complications occurred, 

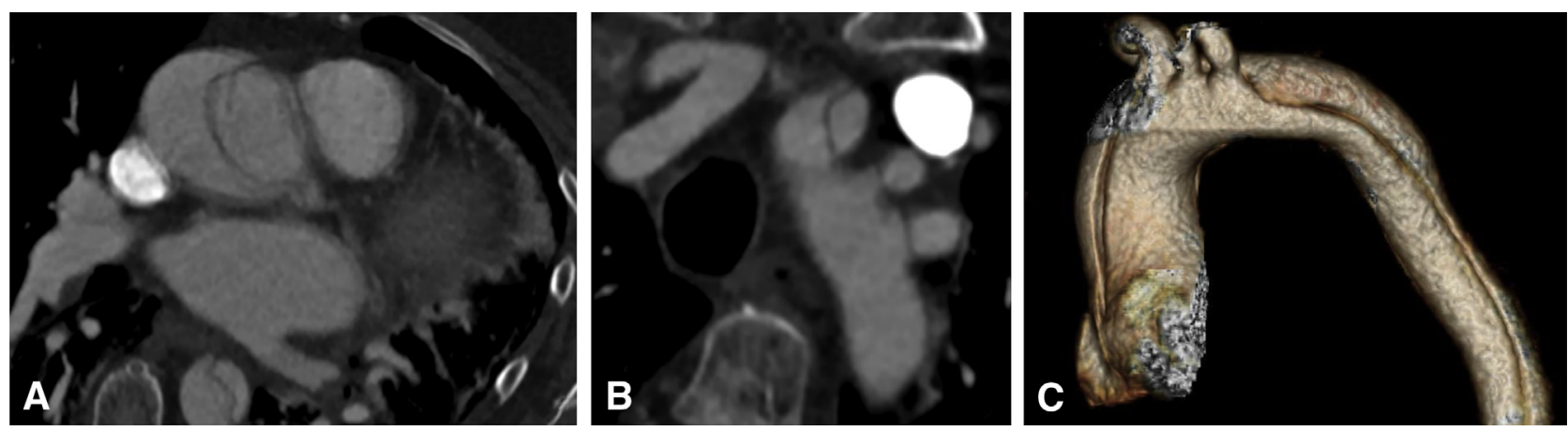

FIGURE 1. Preoperative computed tomographic scans. A, Involvement of the aortic root at the level of the coronary ostium. B, Involvement of the epiaortic vessels' origins. C, Three-dimensional reconstruction of aortic dissection.

intensive care unit stay was 3 days, and the patient was referred to the rehabilitative center on the 6th postoperative day. At 6-month follow-up, the patient was leading a normal life, and check-up assessments revealed good surgical results.

\section{DISCUSSION}

The treatment of coronary dissection represents a surgical challenge and increases the risk of mortality and morbidity for aortic dissection by as much as $6.1 \%$ to $11.3 \%$. $^{1,2}$

Several classifications of coronary involvement in aortic dissection have been proposed. Neri and colleagues ${ }^{3}$ distinguish 3 main types of lesions according to the extension of the dissection flap within the coronary artery. They describe a range of situations, from the isolated ostial dissection to the circumferential detachment with inner intussusception. ${ }^{3}$ Unfortunately, the coronary lesion presented in our report does not match the classification of Neri and colleagues, ${ }^{3}$ given the intramural vessel course and the anomalous origin.
Despite concerns regarding graft obstruction, one of the indications for the Cabrol technique remains aortic dissection with coronary involvement. In fact, the Cabrol procedure provides a tension-free anastomosis of the coronary arteries to the aortic conduit in the presence of malacic vascular tissue and a limited chance of mobilization of the vessels. $^{4}$

Another surgical solution is the coronary ostial ligature and coronary artery bypass grafting. This should be considered a rescue procedure for the competitive flow and coronary re-dissection risk with the complete graft-dependent perfusion of large myocardium myocardial territories. ${ }^{3}$

Because of the dubious results of the Cabrol procedure and coronary artery bypass grafting in this specific disease, a coronary repair technique has recently been described that uses patch interposition with either saphenous vein or bovine or equine pericardium. Westaby and associates ${ }^{5}$ suggest the use of a semicircular hood pericardial patch to avoid coronary tension, but only in elective surgery.

With respect to our urgent case, we were faced with 2 surgical challenges: first, the involvement in the dissection of
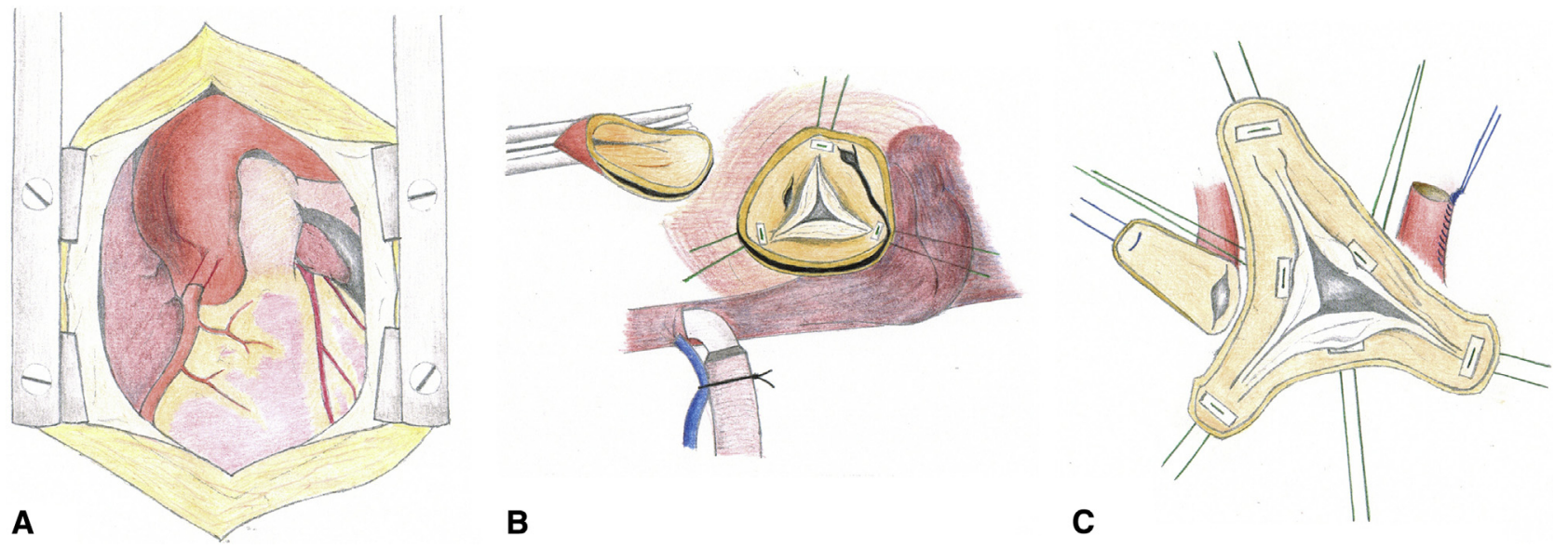

FIGURE 2. A, Surgical view of type A aortic dissection with the intramural right coronary artery pattern. B, Anomalous intramural right coronary artery course. C, Isolation of the right proximal coronary artery tract. 


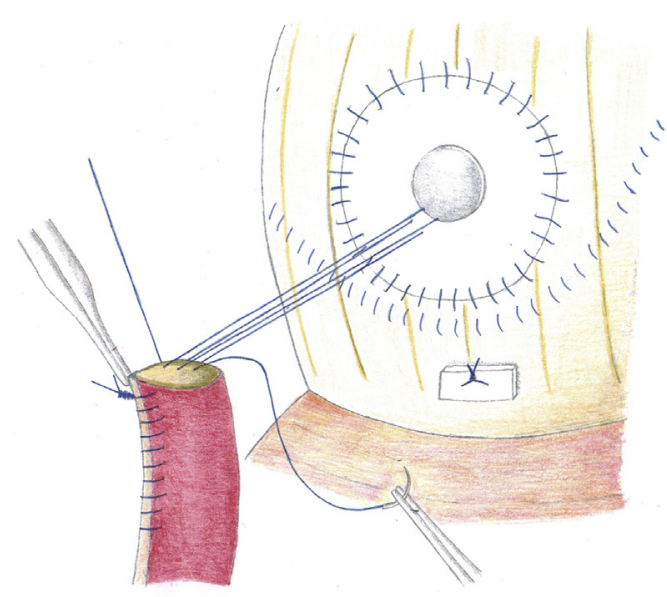

A

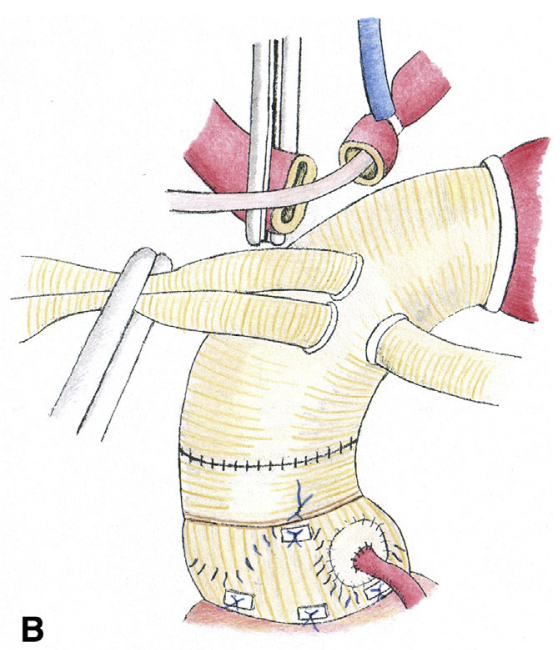

B

FIGURE 3. A, Coronary plasty of right coronary artery. B, Final complete repair

the RCA; and second, the RCA's anomalous origin and course. We demonstrate here an alternative 3-step surgical technique to reconstruct and reimplant the RCA onto the neoaortic root by interposing a bovine pericardial patch. This procedure provides an anatomic reimplantation of

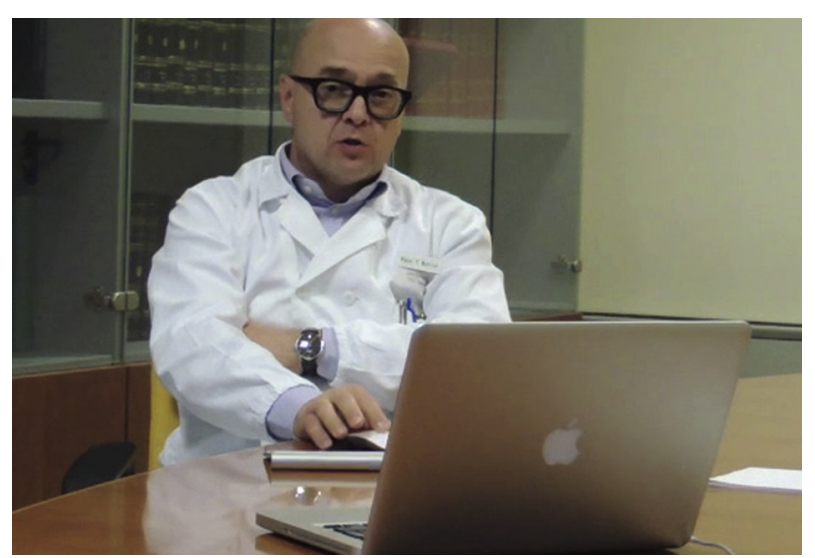

VIDEO 1. Commentary of one of the authors (T.B.) discussing the relevance of the article. Video available at: https://www.jtcvs.org/article/ S0022-5223(18)31551-4/fulltext. the coronary vessel, even in the case of anomalous origin and intramural course. Furthermore, unlike the Cabrol technique, it preserves the physiologic pattern of coronary flow. Finally, the anastomosis between 2 biologic surfaces (bovine pericardium and coronary artery) reduces the risk of surgical bleeding, which is especially useful in emergency surgery (Video 1).

\section{References}

1. Waterford SD, Di Eusanio M, Ehrlich MP, Reece TB, Desai ND, Sundt TM, et al. Postoperative myocardial infarction in acute type A aortic dissection: a report from the International Registry of Acute Aortic Dissection. J Thorac Cardiovasc Surg. 2017; 153:521-7.

2. Geirsson A, Szeto WY, Pochettino A, McGarvey ML, Keane MG, Woo YJ, et al. Significance of malperfusion syndromes prior to contemporary surgical repair for acute type A dissection: outcomes and need for additional revascularizations. Eur J Cardiothorac Surg. 2007;32:255-62.

3. Neri E, Toscano T, Papalia U, Frati G, Massetti M, Capannini G, et al. Proximal aortic dissection with coronary malperfusion: presentation, management, and outcome. J Thorac Cardiovasc Surg. 2001;121:552-60.

4. Kourliouros A, Soni M, Rasoli S, Grapsa J, Nihoyannopoulos P, O’Regan D, et al. Evolution and current applications of the Cabrol procedure and its modifications. Ann Thorac Surg. 2011:91:1636-41.

5. Westaby S, Katsumata T, Vaccari G. Coronary reimplantation in aortic root replacement: a method to avoid tension. Ann Thorac Surg. 1999;67: 1176-7. 